\title{
A Three-Dimensional-reconstruction-based study on the ocular volume of Chinese children with high myopia
}

\author{
Xiaodan Jiang ${ }^{1 *}$, Hongwei Deng ${ }^{2 *}$, Chun Lung ${ }^{3}$, Fanyin Wang ${ }^{1}$, Shuang $\mathrm{Li}^{1}$, Yanni Jiang ${ }^{1}$ and Mingyue Wang ${ }^{1}$
}

\begin{abstract}
Background: Highly myopic eyes differ in morphology from emmetropic eyes, and the correct estimation of the vitreous volume is difficult. To explore an effective method to estimate ocular volume using refractive factors in children.

Methods: This is a retrospective study of children with high myopia who visited the Shenzhen Shekou People's Hospital (July-December 2018) before undergoing posterior scleral reinforcement surgery. Data on refractive factors and ocular 3D reconstruction imaging based on high-end CT were collected for linear correlation and linear regression analyses.

Results: Ten patients (20 eyes) were included. There are nine males and one female. They were 4 to 12 years of age. The spherical equivalent ranges from +0.25 to $-20.00 \mathrm{D}$. The cylindrical equivalent ranges from -0.50 to -6.25 D. The AL(axial length, AL) ranges from 21.78 to $33.90 \mathrm{~mm}$. The corneal curvature (mean) ranges from 42.44 to 46.75. The 3D reconstruction of the CT images shows that the ocular volume ranges from 4.591 to $10.988 \mathrm{ml}$. The ocular volume of the 20 eyes decreases with the increase of diopter and total curvature, both presenting a linear trend, with the Pearson correlation coefficients being $-0.776(P<0.001)$ and $-0.633(P=0.003)$, respectively. The ocular volume of the 20 eyes increases with the increasing $\mathrm{AL}$, also presenting a linear trend, with the Pearson correlation coefficient being $0.939(P<0.001)$.
\end{abstract}

Conclusions: In children, the ocular volume is negatively and linearly correlated with the diopter and curvature, and positively and linearly correlated with the AL.

Keywords: Children, High myopia, Ocular volume, Computed tomography

\section{Background}

The incidence of high myopia is rising sharply worldwide. About 163 million people around the world have high myopia, accounting for $27 \%$ of the total population [1-4]. Asia, especially East Asia, is a high incidence

\footnotetext{
*Correspondence: 814288650@qq.com; dhw110@126.com

'Ophthalmology Department, Shenzhen Shekou People's Hospital, No.36 Gongye 7th Road, Shekou, Nanshan District, 518067 Shenzhen, China ${ }^{2}$ Department of Strabismus \& Pediatric Ophthalmology, Shenzhen Eye Hospital affiliated to Jinan University, The School of Optometry of Shenzhen University, No.18 of Zetian Street, Futian District, 518000 Shenzhen, China Full list of author information is available at the end of the article
}

region of high myopia, and China is one of the countries with the highest incidence $[4,5]$. High myopia can lead to myopia traction maculopathy, myopic choroidal neovascularization, and arched macular degeneration [6-8], and is, therefore, the second leading cause of low vision and blindness in the Chinese population [9].

There is a lack of effective ways to prevent or control high myopia. Existing treatments are focusing on controlling the increase of the axial length and curing common complications $[10,11]$. Among them, surgical treatments include vitrectomy, internal limiting membrane removal,

(c) The Author(s). 2021 Open Access This article is licensed under a Creative Commons Attribution 4.0 International License, which permits use, sharing, adaptation, distribution and reproduction in any medium or format, as long as you give appropriate credit to the original author(s) and the source, provide a link to the Creative Commons licence, and indicate if changes were made. The images or other third party material in this article are included in the article's Creative Commons licence, unless indicated otherwise in a credit line to the material. If material is not included in the article's Creative Commons licence and your intended use is not permitted by statutory regulation or exceeds the permitted use, you will need to obtain permission directly from the copyright holder. To view a copy of this licence, visit http://creativecommons.org/licenses/by/4.0/ The Creative Commons Public Domain Dedication waiver (http://creativecommons.org/publicdomain/zero/1.0/) applies to the data made available in this article, unless otherwise stated in a credit line to the data. 
internal limiting membrane packing, posterior scleral reinforcement, and intravitreal injection of anti-vascular endothelial growth factor [12-14]. For example, for rhegmatogenous retinal detachment, one of the common complications of high myopia, intravitreal injection of exogenous filling is required in the reduction surgery for retinal detachment and posterior vitrectomy $[15,16]$.The amount of filling and intraocular pressure (IOP) control directly determines the prognosis of retinal reattachment $[15,16]$, but it is subject to subjective judgments as the vitreous volume of highly myopic eyes varies greatly between individuals [17]. Although some scholars have paid attention to the morphology of posterior scleral staphyloma and the thinning of intraocular optic nerve after the axial length elongation $[18,19]$, few scholars have studied the problem of enlarged eyeball volume, which is really a problem that needs the attention of surgeons before vitrectomy and posterior scleral reinforcement. In addition, the evaluation of the filling amount of silicone oil and the size of the customized artificial vitreous body requires the acknowledgment of the vitreous volume. A method to estimate the volume by diopter might provide quantitative data for clinical practice.

The in vivo measurements on the diameter line and eyeball shape for studies on ocular volume are rare in China. Using X-ray technology, Vohra et al. [20] reported in 2000 that the increase in the length of myopic eyes is much higher than that of width and height. Highly myopic eyeballs have an asymmetric growth, which is mainly reflected in the changes of the vitreous body [21]. Feng et al. [22] found that the total intraocular volume and vitreous volume of highly myopic eyes differ from those of emmetropic eyes, which is positively correlated with the diopter, while the volume of the anterior ocular segment and the crystalline lens of highly myopic eyes differ little from emmetropic eyes. Therefore, this evidence suggests that the increase of vitreous volume in highly myopic eyes leads to the increase of total intraocular volume, while the volume of the anterior ocular segment and the crystalline lens remains unchanged.

Nevertheless, data about vitreous volume in highly myopic eyes is missing. Therefore, this study aims to explore an effective method to estimate ocular volume using refractive factors. This could provide a simple method to estimate the vitreous volume without the need for sophisticated equipment and should provide data for individualized precision treatment for patients undergoing vitreoretinal surgery or needing implantation of an artificial vitreous body.

\section{Methods}

\section{Study design and patients}

This is a retrospective study of children with high myopia who visited the Ophthalmology Department of
Shenzhen Shekou People's Hospital from July to December 2018. The study was approved by the Medical Ethics Committee of Shenzhen Shekou People's Hospital. The requirement for individual consent was waived by the committee because of the retrospective nature of the study.

The inclusion criteria are 1) $<18$ years of age, 2) diagnosed with high myopia (>-6.0 D) of one or both eyes, and 3) with complete imaging information. The exclusion criteria are (1) a history of eye injury or (2) periorbital or paranasal sinus disease. The patients underwent ocular and periocular structure examinations using a high-end CT scanning system because they needed to be ruled out orbital deformity and paranasal sinus inflammation before undergoing monocular post-capsule reinforcement surgery.

\section{Data collection}

Detailed information on the ocular refractive factors of the included patients was collected. Sex, age, vision, corneal curvature, ocular AL, and refraction information were recorded. After pupil dilation with one drop of compound tropicamide eye drops $0.5 \%$ (Shenyang Sinqi Pharmaceutical Co., Ltd., Shenyang, China), the patients underwent optometry and ocular bio-measurements, with relevant data recorded. An RT 5100 integrated optometrist system (NIDEK, Tokyo, Japan) was used for computerized optometry, and a LS 900 biometer (HaagStreit Holding, Koniz, Switzerland) was used for optical biometry. In the ametropia examination, each subject underwent five repeated binocular refraction examinations, and a mean value was calculated from the five measured values recorded.

\section{Computed Tomography scan and Three-Dimensional reconstruction}

Three-Dimensional Computed Tomography Scan Images were acquired using a 256-slice multiple detector computed tomography (Revolution CT) scanner (GE Medical Systems LLC, Waukesha, WL 53,188, USA), with $256 \times 0.625 \mathrm{~mm}$ collimation. No contrast agent was given. Reconstrutions were obtained at using a smooth reconstruction kernel, with a slice thickness of $0.625 \mathrm{~mm}$ and increment of 0.3125 . Revolution CT datasets were analyzed using the 3D Medtech Reconstruction System by CAS-Medi-vision Company Limited.

Figure $13 \mathrm{D}-\mathrm{CT}$ screenshots for the patient with myopia 3 diopters in right eye and 14.5 diopters in left eye are two different eyeballs in size shows how we get the original plane data. The first step: A slice of CT images. The second step: Draw lines on the inner surface of the eyeball (shows in green line in Fig. 1). The third step: reconstruction of the 3CT. 


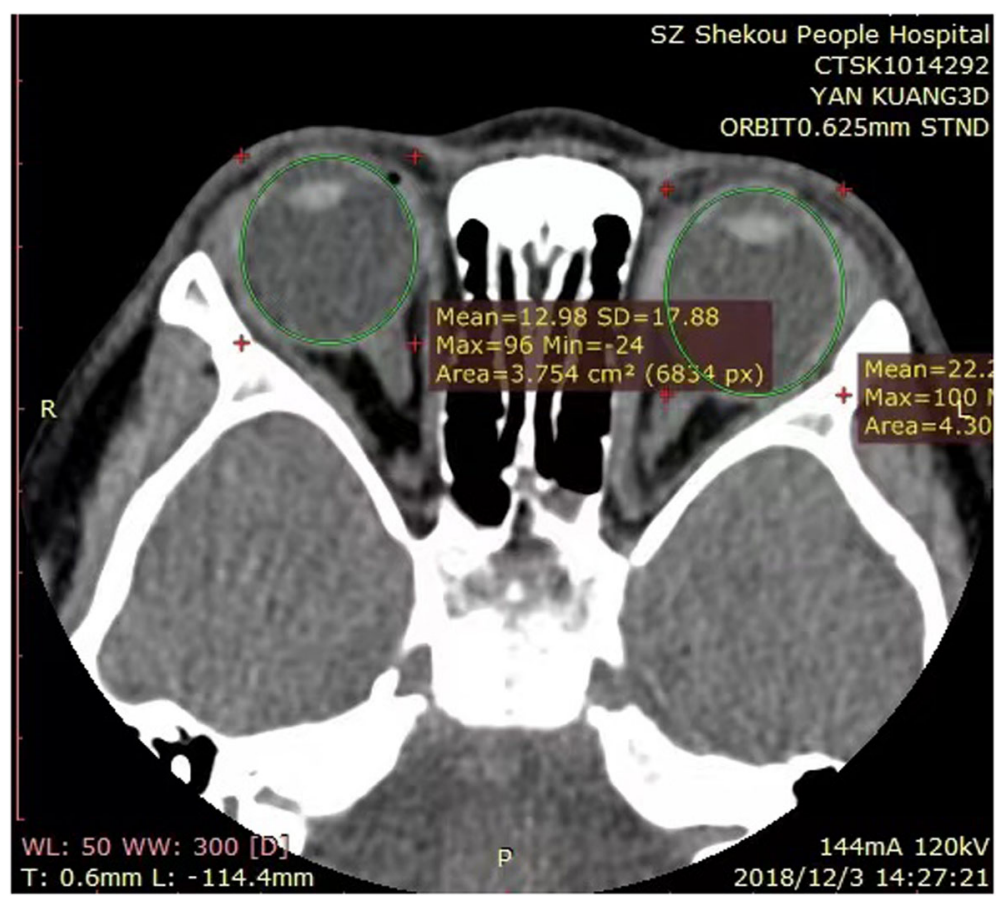

Fig. 1 Pearson correlation analyses between the ocular volume and A diopter $(r=-0.776, P<0.001)$, B corneal curvature $(r=-0.633, P=0.003)$, and C axial length $(r=0.939, P<0.001)$ in 20 eyes from 10 children

\section{Statistical method}

SPSS 20.0 (IBM Corp., Armonk, NY, USA) was used for statistical analysis. Continuous data conforming to the normal distribution are expressed as means standard deviations $( \pm)$; those not conforming to the normal distribution are expressed as medians (ranges). Categorical data are expressed as 5 (\%). Pearson correlation and regression analyses were performed. Twosided $P$-values $<0.05$ are considered statistically significant.

\section{Results}

\section{Characteristics of the patients}

Ten patients (20 eyes) were included. There are nine males and one female. The age range from 3 to 12 , mean 6 years of age $(6 \pm 2.90)$. The spherical equivalent ranges from +0.25 to -20.00 D. The cylindrical equivalent ranges from -0.50 to $-6.25 \mathrm{D}$. The axial length ranges from 21.78 to $33.90 \mathrm{~mm}$. The corneal curvature (mean) ranges from $42.44 \mathrm{D}$ to $46.75 \mathrm{D}$. The $3 \mathrm{D}$ reconstruction of the CT images shows that the ocular volume ranges from 4.591 to $10.988 \mathrm{ml}$.

\section{Correlation analyses}

As shown in the scatter diagram in Fig. 2, the ocular volume of the 20 eyes decreases with the increase of diopter and total curvature, both presenting a linear trend, with the Pearson correlation coefficients being
- $0.776(P<0.001)$ and $-0.633(P=0.003)$, respectively. The ocular volume of the 20 eyes increases with the increasing $\mathrm{AL}$, also presenting a linear trend, with the Pearson correlation coefficient being $0.939(P<0.001)$. Hence, the ocular volume is negatively and linearly correlated with the diopter and curvature, and positively and linearly correlated with the AL.

\section{Linear regression analyses}

The linear regression equation between ocular volume and total diopter was $y=4741.596-203.714 x$. In this case, the determination coefficient was 0.603 , indicating that the total diopter accounted for only $60.3 \%$ of the volumetric change. The linear regression equation between ocular volume and curvature was $y=39,851-753.144 x$. In this case, the determination coefficient was 0.401 , indicating that the curvature accounted for only $40.1 \%$ of the volumetric change. The linear regression equation between ocular volume and AL was $y=6814.273+$ 513.673x. In this case, the determination coefficient was 0.939, indicating that the AL accounted for $93.9 \%$ of the volumetric change.

\section{Discussion}

Highly myopic eyes differ in morphology from emmetropic eyes, and the correct estimation of the vitreous volume is difficult [17]. This study aims to explore an 


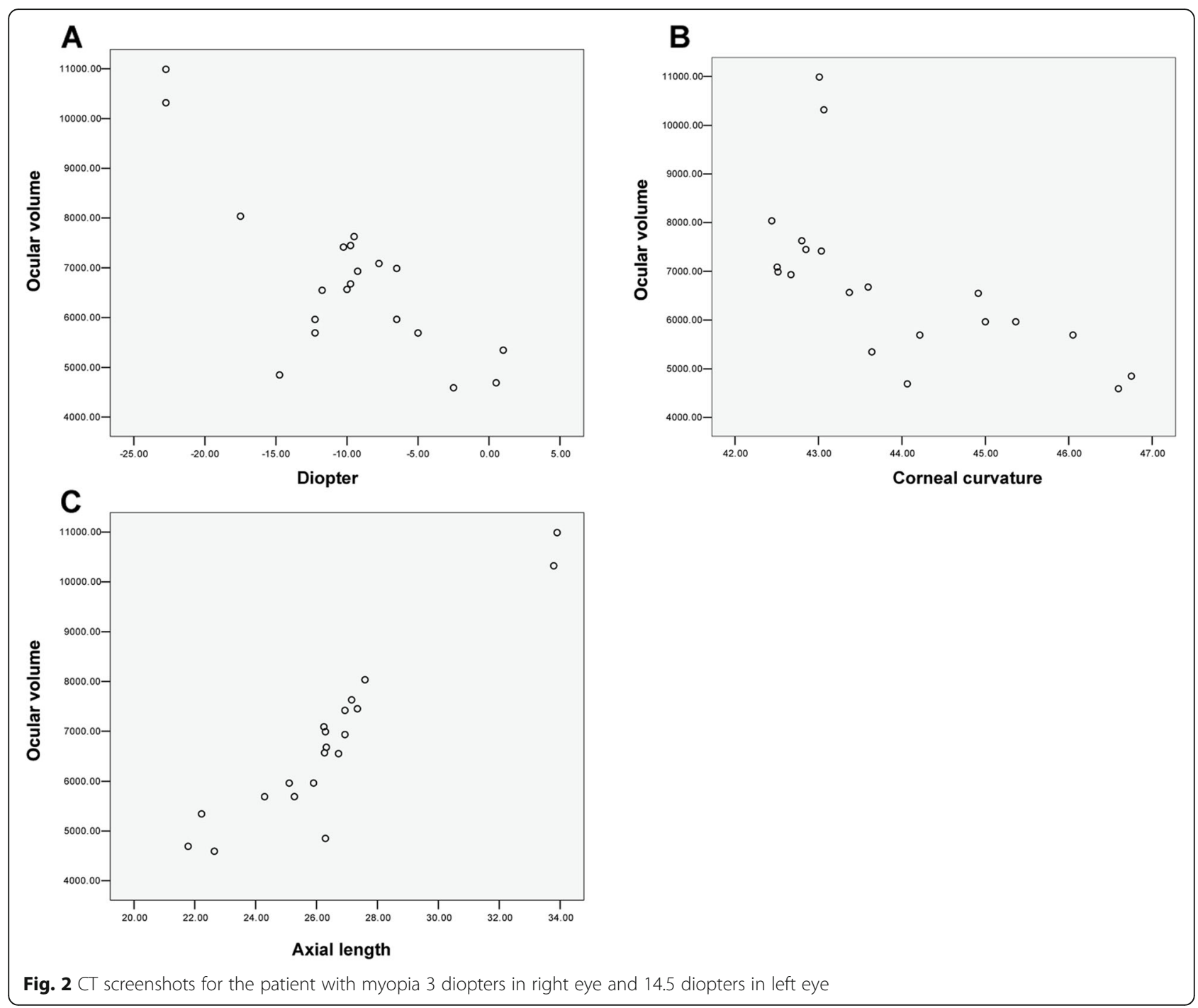

effective method to estimate ocular volume using refractive factors in children. Using high-end CT 3D reconstruction data, the results indicate that in children, the ocular volume is negatively and linearly correlated with the diopter and curvature, and positively and linearly correlated with the AL.

Highly myopic eyeballs have asymmetric growth, as characterized by the elongation of the ocular equator, expansion of the posterior pole, and multi-directional and spherical ocular expansion [21]. Atchison et al. [23] showed that compared with emmetropic eyes, myopic eyes are elongated, more in length than in height, and even less in width. Bron et al. [24] suggest that the bone wall around the eyeball is closer to the eyeball than that behind it in terms of the anatomic relationship between the eyeball and the orbital bone wall; therefore, the anterior and posterior diameters of the eyeball change significantly more than the vertical and horizontal diameters. The reasons for this might be that the osseous structure of the orbit limits the expansion direction of the eyeball, and some ocular factors might cause different changes in the diameters of highly myopic eyeballs. Assuming that defocusing leads to myopia and that the ocular development may be affected by retinal development, the reason for greater anterior and posterior diameters than vertical and horizontal diameters in highly myopic eyeballs may be that the equator has milder defocusing than the posterior pole [24]. The uneven distribution of retinal growth factors might also affect ocular development [25, 26], but it still lacks strong evidence to support it. Cheng et al. [27] measured the thickness of scleral and choroidal tissues of eight subjects with mild-to-moderate hyperopia, six with emmetropia, and seven with mild-to-moderate myopia, and found that subjects with myopia had thinner sclera and choroid than the subjects of the other two groups, 
and such extension of sclera and choroid caused an expanded vitreous body.

This study shows that the ocular volume is correlated with diopter, total curvature, and AL. Linear regression equations were also determined. This is supported by Nagra et al. [28], who revealed that the ocular volume could be estimated using the AL. The determination of the ocular volume of a patient with high myopia will enable more efficient planning before surgery, such as customizing an artificial vitreous body that fits the size of the patient's eyeball and determining the needed amount of silicon oil or expansive gas during surgery. This would be beneficial to the patient's postoperative recovery and might reduce postoperative complications (e.g., anterior segment ischemia syndrome, postoperative ocular hypertension, postoperative ocular hypotension, and retinal re-detachment). Future studies will have to examine the applicability of those equations in real-world clinical practice. Validation in large cohorts is necessary.

The estimation of the eye volume by CT has been shown to be feasible [29], but it is not practical and should not be done in all patients. Indeed, CT examination and 3D reconstruction require time and human resources, and consuming such resources might be unnecessary if simple and reliable equations can be designed. In addition, radiation exposure remains an issue, particularly in children.

This is an exploratory study, but as high-end CT technology has yet to be widely used in ophthalmic examinations, this study was affected by a small sample size and selection bias. Future studies should include more high myopia patients, including adult patients, to verify and improve the ocular volume estimation model, and promote the application of high-end CT in ophthalmology in selected cases. Currently, studies on ocular morphology require the manual collection of images, which is time and labor cost consuming. We expect big data collection and analysis by artificial intelligence for a way to determine the ocular volume by refractive factors and hope to design patient-friendly surgery for severe eye disease before surgery.

\section{Conclusions}

In children, the ocular volume is negatively and linearly correlated with the diopter and curvature, and positively and linearly correlated with the AL. This will lay a theoretical foundation for future studies on the ocular volume of patients of different diopters.

\section{Abbreviations}

IOP: Intraocular pressure.; CT: Computed tomography.

\section{Authors' contributions}

$\mathrm{XJ}$ contributed to design of project, analysis, wrote and critically revised the manuscript. HD participated in patient recruitment, and provided patient's optometry and axial length results. JK was responsible for 3D reconstruction technology and data acquisition.SL helped to draft the manuscript. FW was responsible for statistical analysis. MW contributed to collection of image data. YJ contributed to collection of medical records. All authors read and approved the final manuscript.

\section{Funding}

International Science and Technology Cooperation Research Project of Shenzhen Science and Technology Innovation Committee (GJHZ20190821113401670); Sanming Project of Medicine in Shenzhen(SZSM201812090); Shenzhen Fund for Guangdong Provincial Highlevel Clinical Key Specialties (No.SZGSP014).

Availability of data and materials

The datasets used and/or analyzed during the current study are available from the corresponding author on reasonable request.

\section{Declarations}

Ethics approval and consent to participate

The study was approved by the Medical Ethics Committee of Shenzhen Shekou People's Hospital. The requirement for individual consent was waived by the committee because of the retrospective nature of the study. All methods were carried out in accordance with relevant guidelines and regulations for this retrospective study.

Consent for publication

Not applicable.

\section{Competing interests}

The authors declare that they have no competing interests.

\section{Author details}

'Ophthalmology Department, Shenzhen Shekou People's Hospital, No.36 Gongye 7th Road, Shekou, Nanshan District, 518067 Shenzhen, China ${ }^{2}$ Department of Strabismus \& Pediatric Ophthalmology, Shenzhen Eye Hospital affiliated to Jinan University, The School of Optometry of Shenzhen University, No.18 of Zetian Street, Futian District, 518000 Shenzhen, China.

${ }^{3}$ CAS-Medi-Vision Company Limited, Zhuhai, China.

Received: 14 November 2020 Accepted: 14 August 2021

Published online: 07 September 2021

References

1. Holden BA, Fricke TR, Wilson DA, Jong M, Naidoo KS, Sankaridurg P, et al. Global Prevalence of Myopia and High Myopia and Temporal Trends from 2000 through 2050. Ophthalmology. 2016;123:1036-42.

2. Wong TY, Ferreira A, Hughes R, Carter G, Mitchell P. Epidemiology and disease burden of pathologic myopia and myopic choroidal neovascularization: an evidence-based systematic review. Am J Ophthalmol. 2014:157:9-25.

3. Wong YL, Saw SM. Epidemiology of Pathologic Myopia in Asia and Worldwide. Asia Pac J Ophthalmol (Phila). 2016;5:394-402.

4. Grzybowski A, Kanclerz P, Tsubota K, Lanca C, Saw SM. A review on the epidemiology of myopia in school children worldwide. BMC Ophthalmol. 2020;20:27.

5. Sun J, Zhou J, Zhao P, Lian J, Zhu H, Zhou Y, et al. High prevalence of myopia and high myopia in 5060 Chinese university students in Shanghai. Invest Ophthalmol Vis Sci. 2012;53:7504-9.

6. Kumar A, Chawla R, Kumawat D, Pillay G. Insight into high myopia and the macula. Indian J Ophthalmol. 2017;65:85-91.

7. Shih YF, Ho TC, Hsiao CK, Lin LL. Visual outcomes for high myopic patients with or without myopic maculopathy: a 10 year follow up study. Br J Ophthalmol. 2006;90:546-50.

8. Cheung CMG, Arnold JJ, Holz FG, Park KH, Lai TYY, Larsen M, et al. Myopic Choroidal Neovascularization: Review, Guidance, and Consensus Statement on Management. Ophthalmology. 2017;124:1690-711. 
9. Wong TY, Ohno-Matsui K, Leveziel N, Holz FG, Lai TY, Yu HG, et al. Myopic choroidal neovascularisation: current concepts and update on clinical management. Br J Ophthalmol. 2015;99:289-96.

10. Lagreze WA, Schaeffel F. Preventing Myopia. Dtsch Arztebl Int. 2017;114: 575-80.

11. Saw SM, Matsumura S, Hoang QV. Prevention and Management of Myopia and Myopic Pathology. Invest Ophthalmol Vis Sci. 2019;60:488-99.

12. Chang JS, Flynn HW, Jr., Engelbert M, Shane AR, Smiddy WE, Chang S. Pars plana vitrectomy in patients with myopic macular retinoschisis. $\mathrm{Br} J$ Ophthalmol. 2014;98:534-7.

13. Shimada N, Ohno-Matsui K, Yoshida T, Sugamoto Y, Tokoro T, Mochizuki M. Progression from macular retinoschisis to retinal detachment in highly myopic eyes is associated with outer lamellar hole formation. $\mathrm{Br} J$ Ophthalmol. 2008;92:762-4.

14. Lai CC, Chen YP, Wang NK, Chuang LH, Liu L, Chen KJ, et al. Vitrectomy with Internal Limiting Membrane Repositioning and Autologous Blood for Macular Hole Retinal Detachment in Highly Myopic Eyes. Ophthalmology. 2015;122:1889-98.

15. Kang HK, Luff AJ. Management of retinal detachment: a guide for nonophthalmologists. BMJ. 2008;336:1235-40.

16. Gariano RF, Kim CH. Evaluation and management of suspected retinal detachment. Am Fam Physician. 2004;69:1691-8.

17. Wu PC, Chen YJ, Chen CH, Chen YH, Shin SJ, Yang HJ, et al. Assessment of macular retinal thickness and volume in normal eyes and highly myopic eyes with third-generation optical coherence tomography. Eye (Lond). 2008; 22:551-5.

18. Frisina $\mathrm{R}$, Martini $\mathrm{G}$. Axial length-related inter-individual variability in the posterior pole morphology of healthy eyes. Int Ophthalmol. 2020;40(11): 2901-11. https://doi.org/10.1007/s10792-020-01474-6.

19. Frisina R, Baldi A, Cesana BM, et al. Morphological and clinical characteristics of myopic posterior staphyloma in Caucasians. Graefe's Arch Clin Exp Ophthalmol. 2016;254(11):1-11.

20. Vohra SB, Good PA. Altered globe dimensions of axial myopia as risk factors for penetrating ocular injury during peribulbar anaesthesia. Br J Anaesth. 2000;85:242-5.

21. Curtin BJ. The myopias: basic science and clinical management. Philadelphia: Harper \& Row; 1985.

22. Feng $W Q$, Zhou $Y X$, Shi MG. The analysis of the dimensional measurement in high myopia by MXI. Ophthalmon China. 2008;17:403-6.

23. Atchison DA, Jones CE, Schmid KL, Pritchard N, Pope JM, Strugnell WE, et al. Eye shape in emmetropia and myopia. Invest Ophthalmol Vis Sci. 2004;45: 3380-6.

24. Bron AJ, Tripathi RC, Tripathi BJ. Wolff's Anatomy of the Eye and Orbit. 8th ed. London: Chapman and Hall; 1997.

25. Smith EL, 3rd, Kee CS, Ramamirtham R, Qiao-Grider Y, Hung LF. Peripheral vision can influence eye growth and refractive development in infant monkeys. Invest Ophthalmol Vis Sci. 2005;46:3965-72.

26. Atchison DA, Pritchard N, Schmid KL, Scott DH, Jones CE, Pope JM. Shape of the retinal surface in emmetropia and myopia. Invest Ophthalmol Vis Sci. 2005;46:2698-707.

27. Cheng HM, Singh OS, Kwong KK, Xiong J, Woods BT, Brady TJ. Shape of the myopic eye as seen with high-resolution magnetic resonance imaging. Optom Vis Sci. 1992;69:698-701.

28. Nagra M, Gilmartin B, Logan NS. Estimation of ocular volume from axial length. Br J Ophthalmol. 2014;98:1697-701.

29. Igbinedion BO, Ogbeide OU. Measurement of normal ocular volume by the use of computed tomography. Niger J Clin Pract. 2013;16:315-9.

\section{Publisher's Note}

Springer Nature remains neutral with regard to jurisdictional claims in published maps and institutional affiliations.

Ready to submit your research? Choose BMC and benefit from:

- fast, convenient online submission

- thorough peer review by experienced researchers in your field

- rapid publication on acceptance

- support for research data, including large and complex data types

- gold Open Access which fosters wider collaboration and increased citations

- maximum visibility for your research: over $100 \mathrm{M}$ website views per year

At BMC, research is always in progress.

Learn more biomedcentral.com/submissions 